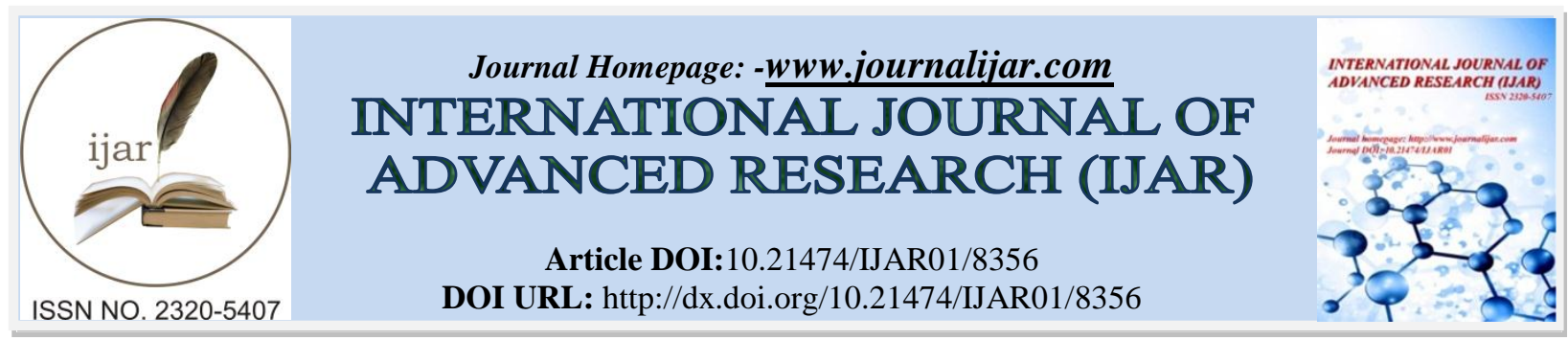

RESEARCH ARTICLE

\title{
THE RELATIONSHIP BETWEEN WELL-BEING, STRESS MANAGEMENT AND MENTAL WELL-BEING OF THE ELDERLY PEOPLE IN BANGKOK.
}

Chanunthakorn Kiatjanon ${ }^{1}$, Ornpapha Chutikorntaweesin ${ }^{2}$ and Thuchapon Yodthong ${ }^{2}$.

1. Ph.D. (Counseling Psychology) Candidate, California University, Los Angeles, California, USA.

2. Associate Professor, California University (FCE), Los Angeles, California, USA.

\section{Manuscript Info}

Manuscript History

Received: 08 November 2018

Final Accepted: 10 December 2018

Published: January 2019

Key words:-

Well-being, Stress Management, Mental Well-being, Elderly People, Bangkok.

\begin{abstract}
The purposes of this research were: (1) to study the components of well-being, stress management, and mental well-being of the elderly people in Bangkok, (2) to analyze the relationship of the variables components of well-being, stress management and mental well-being of the elderly people in Bangkok, and (3) to analyze a causal relationship between well-being, stress management and mental well-being of the elderly people in Bangkok. The results of the study show that well-being (WEL), stress management (STR), and mental well-being (MENWEL) of the elderly people had a relationship with the statistical significance at the level of .01. Its probability value, chi-square probability level, comparative fit index, goodness of fit index, adapted goodness-of-fit index, and root mean square error of approximation were $0.055,1.510,0.990,0.970,0.950$, and 0.036 respectively. Therefore, the model of causal relationship between well-being, stress management and mental well-being of the elderly people in Bangkok was relevant to the empirical data.
\end{abstract}

Copy Right, IJAR, 2017,. All rights reserved.

\section{Introduction:-}

In this century, the rates of aging populations become the world phenomenon. Populations of almost every country are aging; this is because of the impact of birth rate reduction of each country. The world populations have become the so-called "Aging Society" (Foundation of Thai Gerontology Research and Development Institute, 2015).

Thailand is one of the countries that are entering society of elderly people. According to the database population structure, it is estimated that 2018 is the first year that the elderly people will exceed the number of children a hundred of thousands and will continue to increase until 2021, which the proportion of the elderly people will be $20 \%$ increased. Furthermore, in 2036, the number of Thai population will be less than the present with $30 \%$ of the elderly populations, entering "the super aging society" (Wimolsiri, 2017).

The old age is the period of physical changes in the way of deterioration, and is risky to get disease, especially chronic illness which is a major health problem for the elderly people (Phusuwan, 2014). In addition, when people get older and older, their performance of the body and brain will be deteriorated, and their capability in working will also be decreased. There will be the limitation of self-adaptation, which causes stress, anxiety, and suffering in living, leading to reduction of life satisfaction (Trireungworawat, 2017).

Corresponding Author:-Chanunthakorn Kiatjanon.

Address:-Ph.D. (Counseling Psychology) Candidate, California University, Los Angeles, California, USA. 
The life of the elderly people, who have worked with their responsible duties throughout the past, might face the deterioration of physical body, boredom, and depressed mind when they have to stop working and stay at home only. These behaviors, when accumulated, can affect the physical and mental health of the elderly people, especially it can affect the mental problem which is vital factor for good living. The elderly people might think that they cannot earn any income for living or create any benefit anymore; some might think that they are a burden of their descendants. They might think that they are not worth anymore. Duangkaew and Dech-Udom (2007) found that the elderly people who stay at home might have high stress. A lack of interaction with neighbors and capability to participate in activities of village leads to an inability to apply appropriate strategies in managing stress. The research results also show that the personal factors have effects on stress of elderly people. Therefore, the risky group shouldbe taken care of by any agencies or family members in order to prevent and reduce stress levels (Phusuwan, 2014). In case that the elderly people cannot manage their stress, it may cause effects on both physical and mental health; thereby, they should find appropriate methods to manage their stress, for example, relaxing, watching television or movies, listening to songs, playing music, practicing meditation, praying, participating religious activities, changing the thinking process by letting go, and chilling out (Jutha et al., 2012; Talodphop, Pratumtone, Reunkon, and Mopuang, 2014).

The researchers realize the importance of the mentioned problems: the elderly people in Bangkok who have to face these situations, thereby conducting the research on the relationship between well-being, stress management affecting mental well-being. There have been a few researches conducted on this topic. The researchers aimed to find the directions for the elderly people to have good physical and mental health, to be self-esteemed, to understand and adapt to the changing environment; consequently, the elderly people will have mental well-being and can live a happy life in the society.

\section{Research Purposes:-}

1. To study the components of well-being, stress management, and mental well-being of the elderly people in Bangkok.

2. To analyze the relationship of the variables components of well-being, stress management and mental well-being of the elderly people in Bangkok.

3. To analyze a causal relationship between well-being, stress management and mental well-being of the elderly people in Bangkok.

\section{Research Hypotheses:-}

$\mathrm{Ha}_{1}$ Well-being, stress management and mental well-being of the elderly people in Bangkok have a relationship with the statistical significance.

$\mathrm{Ha}_{2}$ Well-being is the factor affecting mental well-being of the elderly people in Bangkok.

$\mathrm{Ha}_{3}$ Stress management is the factor affecting mental well-being of the elderly people in Bangkok.

$\mathrm{Ha}_{4}$ The model of a causal relationship between well-being, stress management and mental well-being of the elderly people in Bangkok is relevant to the empirical data.

\section{Research Paradigm:-}

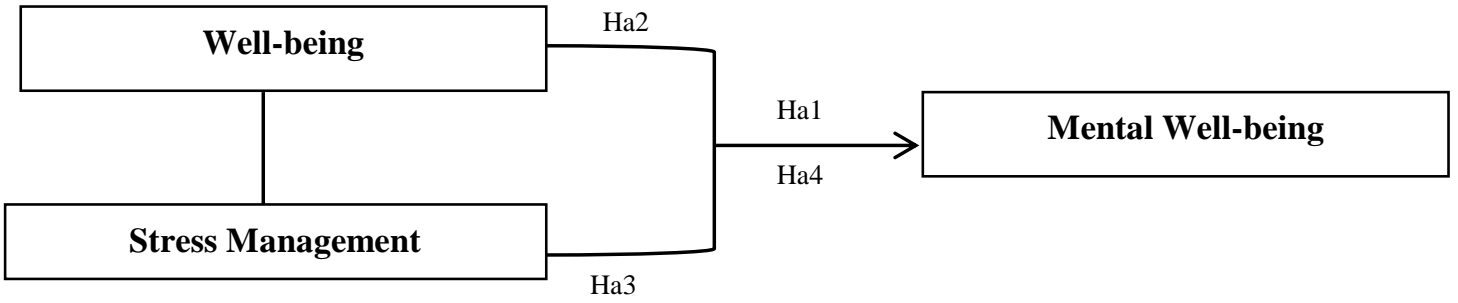

Figure 1:-Research paradigm

\section{Research Methodology:-}

The researchers applied the quantitative research method in this study. The populations of this research were 19,827 elderly people aged more than 60 years in Bangkok, who are the members of elderly club in the community (Social Development Office of Bangkok Metropolitan Administration, 2017). The researchers identified the sample size by using the table of Taro Yamane, retrieving 386 samples. The research tool of this research was the questionnaire 
which has been used to try-out with 30 virtual samples in order to find the Alpha Coefficient of Cronbach, and derived the reliability coefficient of .953 . The researcher studied the secondary data by reviewing the concepts, theories, and related research from documents from both domestic and international sources. The statistics used in this research consisted of frequency, percentage, mean, standard deviation, Pearson Correlation, and Linear Structural Relationship Model (LISREL Model).

\section{Research Results:-}

The analysis about demographic profiles:-

With regard to the demographic profiles of all 386 respondents, who are the elderly people in Bangkok, the results show that $53.60 \%$ were female; $32.60 \%$ were aged between $65-69$ years; $66.60 \%$ were married and lived together; $24.40 \%$ finished the primary school; $82.40 \%$ lived with their family; and $35.00 \%$ were unemployed.

The analysis of well-being of the elderly people in Bangkok:-

With regard to the well-being of elderly people in Bangkok, in total, its practice was at frequent level $(\bar{X}=4.04$, S.D. $=0.50)$. In particular, Physical had the highest mean score $(\bar{x}=4.27$, S.D. $=0.51)$, followed by Social $(\bar{X}=4.02$, S.D. $=0.78)$, Mental $(\bar{X}=4.01$, S.D. $=0.57)$, and Spiritual $(\bar{X}=3.85$, S.D. $=0.60)$ respectively (see table 1).

Table 1:-Mean and standard deviation of well-being of the elderly people in Bangkok.

\begin{tabular}{|l|c|c|c|c|}
\hline \multicolumn{1}{|c|}{ Well-being of elderly people in Bangkok } & $\overline{\mathrm{X}}$ & S.D. & Translation & Ranking \\
\hline 1. Physical & 4.27 & 0.51 & Highest Frequent & 1 \\
\hline 2. Mental & 4.01 & 0.57 & Frequent & 3 \\
\hline 3. Social & 4.02 & 0.78 & Frequent & 2 \\
\hline 4. Spiritual & 3.85 & 0.60 & Frequent & 4 \\
\hline \multicolumn{2}{|c|}{$\mathbf{4 . 0 4}$} & $\mathbf{0 . 5 0}$ & Frequent & \\
\hline
\end{tabular}

The analysis of stress management of the elderly people in Bangkok:-

With regard to the stress management of the elderly people in Bangkok, in total, its practice was at frequent level $(\overline{\mathrm{X}}=4.04$, S.D. $=0.37)$. In particular, Accepting the unchangeable had the highest mean score $(\overline{\mathrm{X}}=4.18, \mathrm{~S} . \mathrm{D} .=$ 0.47), followed by Changing the situations $(\bar{x}=4.18$, S.D. $=0.59)$, Life management in best way $(\bar{x}=4.05$, S.D. $=$ 0.56), Letting go $(\bar{x}=3.94$, S.D. $=0.54)$, and Taking control of your environment $(\bar{x}=3.87$, S.D. $=0.51)$ respectively (see table 2 ).

Table 2:-Mean and standard deviation of stress management of the elderly people in Bangkok.

\begin{tabular}{|l|c|c|c|c|}
\hline Stress management of elderly people in Bangkok & $\bar{X}$ & S.D. & Translation & Ranking \\
\hline .1Changing the situations & 4.18 & 0.59 & Frequent & 2 \\
\hline .2Accepting the unchangeable & 4.18 & 0.47 & Frequent & 1 \\
\hline .3Letting go & 3.94 & 0.54 & Frequent & 4 \\
\hline .4Life management & 4.05 & 0.56 & Frequent & 3 \\
\hline .5Take control of your environment & 3.87 & 0.51 & Frequent & 5 \\
\hline In total & $\mathbf{4 . 0 4}$ & $\mathbf{0 . 3 7}$ & Frequent & \\
\hline
\end{tabular}

The analysis of mental well-being of the elderly people in Bangkok:-

With regard to the mental well-being of the elderly people in Bangkok, in total, the mental well-being was at high level $(\overline{\mathrm{X}}=4.17$, S.D. $=0.44)$. In particular, Positive relations with others had the highest mean score $(\overline{\mathrm{X}}=4.20$, S.D. = 0.47), followed by Personal growth $(\bar{X}=4.18$, S.D. $=0.64)$, Interdependence $(\bar{X}=4.17$, S.D. $=0.64)$, Life satisfaction $(\bar{x}=4.16$, S.D. $=0.51)$, and Self-acceptance $(\bar{x}=4.15$, S.D. $=0.57)$ respectively (see table 3$)$.

Table 3:-Mean and standard deviation of mental well-being of the elderly people in Bangkok

\begin{tabular}{|l|c|c|c|c|}
\hline \multicolumn{1}{|c|}{ Mental well-being of elderly people in Bangkok } & $\overline{\mathrm{X}}$ & $\mathbf{S . D .}$ & Translation & Ranking \\
\hline 1. Positive relations with others & 4.20 & 0.47 & High & 1 \\
\hline 2. Interdependence & 4.17 & 0.64 & High & 3 \\
\hline 3. Life satisfaction & 4.16 & 0.51 & High & 4 \\
\hline 4. Self-acceptance & 4.15 & 0.57 & High & 5 \\
\hline 5. Personal growth & 4.18 & 0.64 & High & 2 \\
\hline \multicolumn{1}{|c|}{ In total } & $\mathbf{4 . 1 7}$ & $\mathbf{0 . 4 4}$ & High \\
\hline
\end{tabular}


The analysis of relationship between the component factors of well-being, stress management and mental well-being of the elderly people in Bangkok:-

With regard to the correlation between well-being (WEL), stress management (STR) and mental well-being (MENWEL), these three variables had the relationship with the statistical significance at the level of .01. The correlations of the relationships were as follows:

The correlation of the relationship between well-being (WEL) and mental well-being (MENWEL) was .623, which was the highest correlation.

The correlation of the relationship between stress management (STR) and mental well-being (MENWEL) was .530 (see table 4).

Table 4:-Correlation of well-being, stress management and mental well-being of the elderly people in Bangkok

\begin{tabular}{|c|c|c|c|}
\hline Factors & WEL & STR & MENWEL \\
\hline WEL & 1 & & \\
\hline STR & $.496^{* *}$ & 1 & 1 \\
\hline MENWEL & $.623^{* *}$ & $.530^{* *}$ & \\
\hline
\end{tabular}

** with the statistical significance at level of .01

The analysis of the linear relationship between well-being, stress management and mental well-being of the elderly people in Bangkok:-

The model of causal relationship between well-being, stress management and mental well-being of the elderly people in Bangkok was relevant to the empirical data. Its probability value, chi-square probability level, comparative fit index, goodness of fit index, adapted goodness-of-fit index, root mean square error of approximation, andstandardized root mean squared residual were $0.055,1.510,0.990,0.970,0.950,0.036$ and 0.050 respectively. Therefore, the model of causal relationship between well-being, stress management and mental well-being of the elderly people in Bangkok was relevant to the empirical data.

The factor loading of well-being on mental well-being of the elderly people in Bangkok was 0.55. The factor loading of stress management on mental well-being of the elderly people in Bangkok was 0.53 (see figure 2).

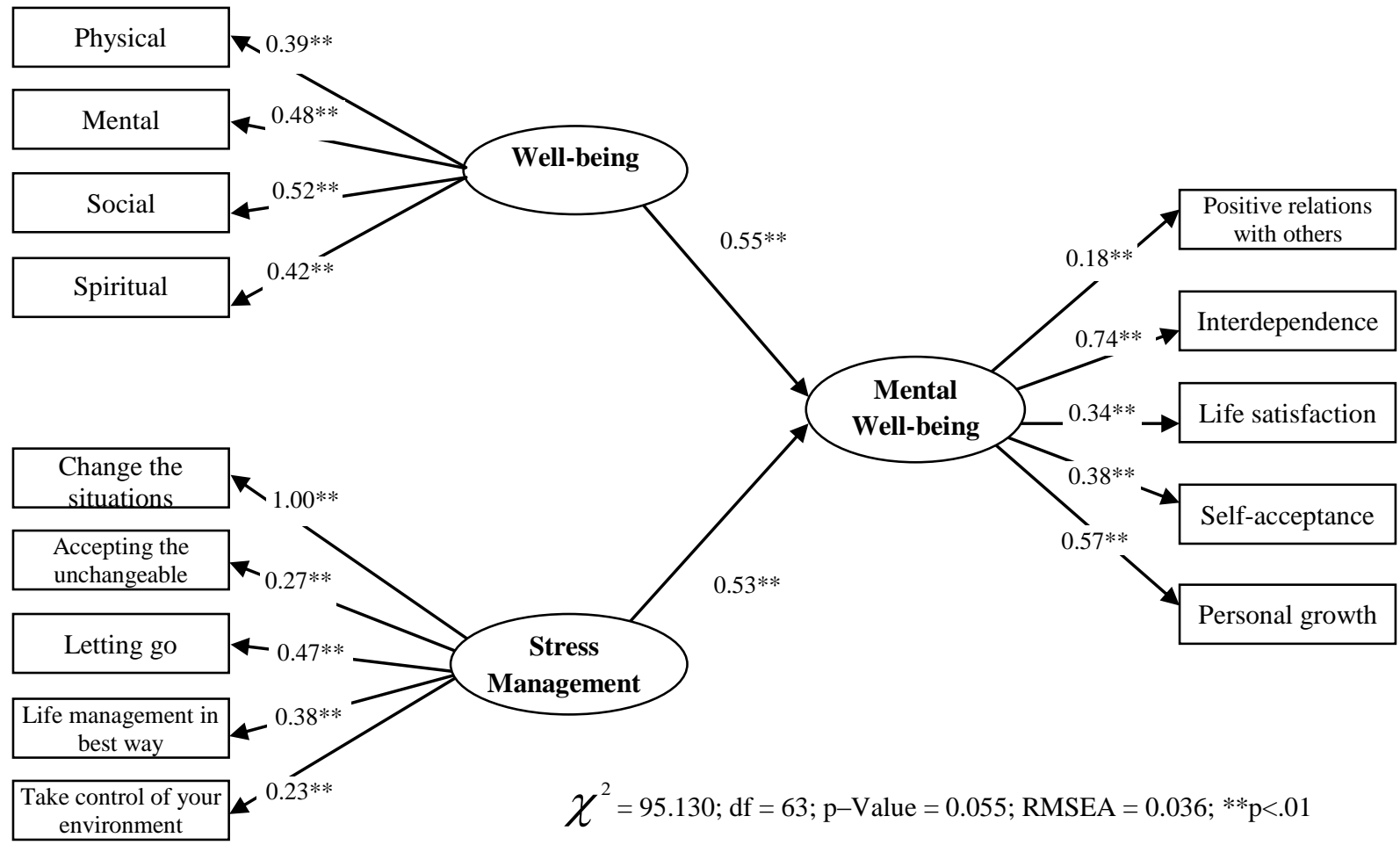

Figure 2:-The results of analysis of the LISREL Model of well-being, stress management and mental well-being of the elderly people in Bangkok created by the researcher 


\section{Discussion:-}

With regard to the well-being of the elderly people in Bangkok, in total, its practice was at very frequent level. In particular, physical health had the highest mean score, followed by social, mental, and spiritual respectively. This is relevant to the concept of Naidoo and Wills (2009) that health is the holistic issue and has a relationship with many related dimensions in terms of external world, surrounding environment, residence society, and the internal dimension of individual. The dimensions of health are divided into 6 aspects: 1) physical health - the strength of body, 2) mental health-the acknowledgement of health condition under one's own belief, 3) emotional health - the capability to fulfill the sentiment, 4) social health - the acknowledgement of supports from family and friends, 5) spiritual health-the acknowledgement and feeling of having goals in living, and 6) sexual health-the achievement of satisfaction of sexual expression. Moreover, Seligman (2011) created PERMA Model which consists of 5 important components about well-being and happiness: 1) positive emotions - not only the smile but to be optimistic and to have positive thinking on the past, present, and future, 2) engagement - the activities in living are important for learning, growing, and nurturing the personal happiness, 3) relationships - creating positive relationship with parents, relatives, colleagues, and friends is an important methods in sharing love and joy, 4) meaning - to answer the question why we were born to the world, which is to live happily and accomplish goals, and 5) achievement - to have goals and ambition in living to achieve the things of success and pride. According to Noiwat (2012), people who have good health in every age of their life will be still healthy in their old age. The components of being healthy are 1) physical health - good body condition without disease, 2) mental health normal mental condition, ability to adapt to social atmosphere in every level, and ability to control the emotions in various situations, and 3) social health - normal living conditions in the society.

With regard to stress management of the elderly people in Bangkok, in total, the practice was at very frequent level. In particular, acceptance of change had the highest mean score, followed by change the situations, life management in best way, letting go, and take control of your environment respectively. This is relevant to the concept of Pender (1996) who presented methods of stress management:1) minimizing the frequency of stress-inducing situation by changing the environment or lifestyle that stimulate stress, 2) increasing resistance to stress in both physical and mental aspects; in the mental aspects, people can change their personalities and self-perception, while in the physical aspects, one method of stress management is to exercise, and 3) counterconditioning to avoid physiological arousal by practicing meditation, relaxing muscle tension, or relaxing by using Biofeedback.

In addition, Channuwong and Kantatian (2012) also suggested strategies for reducing stress: 1) physical exercise, 2) listening to music, 3) creating a sense of humor, 4) breathing exercise, 5) getting massage, 6) getting plenty of rest, 7) looking for a better alternative, 8) coping with anger, 9) reframing thinking, 10) managing worry time, 11) recognizing and disengaging, 12) accepting the inevitable, 13) leaving the past in the past, 14) recognizing one's well-being and sustaining it, 15) learning how to keep smiling during the time of crisis, 16) practicing meditation, and 17) creating positive feeling. Braham (1990) created CALM Model in order to manage the stress: $\mathrm{C}=\mathrm{Change}$, $\mathrm{A}=$ Accept, $\mathrm{L}=$ Let go, $\mathrm{M}=$ Manage life. This is also relevant to the study of Songtub, Suklim, and Raksanam (2013) who found the tricks of stress management consisting of 1) to receive support and care from family and community members by visiting and discussing counseling when problems occur, 2) to exercise or work to make you forget about the stress, 3) to get massage to relax muscles, 4) to use of Dharma to manage stress, such as going to talk with the monks at the temple, listening to Dharma from the radio, praying before bed and meditating, and 5) to organize environments such as having meals with other family members will make the elderly people feel warm and comfortable.

With regard to the mental well-being of the elderly people in Bangkok, in total the mental well-being was at high level. In particular, positive relations with others had the highest mean score, followed by personal growth, interdependence, life satisfaction, and self-acceptance respectively. This is relevant to the concept of Ryff and Keyes (1995) that mental well-being is the satisfaction to achieve success in life-span, which consists of 6 components: 1) self-acceptance in both good and bad side, 2) positive relationship with others as the friendship, 3) self-confidence to be able to make decision by oneself, 4) take control of environment or complicated activities, 5) life goals make life both in the past and present valuable, and 6) personal growth in recognizing one's own performance, improvement, and understanding. In addition, Ketpitchwattana, Sangtienchay, and Angsuroj (2000) presented 5 dimensions of mental well-being: 1) harmony between family members and between friends, 2) interdependence to make themselves useful, 3) peace and acceptance, as well as attempt to accept and find peace of mind, 4) respect, the recognition of respect and honor of the elderly people, and 5) brilliance, freshness, liveliness and joy of the surroundings. Moreover, Ruderman et al. (2002) suggested the concept on mental well-being in 
3 aspects: 1) life satisfaction, 2) self-respect, and self-acceptance. In addition, this is relevant to the concept of Department of Mental Health, Ministry of Public Health (2013) that there are 5 aspects of happiness of the elderly people: 1) comfort - to take good care of physical health to be strong and to respond the physical need depending on the present condition, 2) fun - choosing a pleasant lifestyle with fun activities to create a happy mood, 3) pride life satisfaction, self-pride, self-confidence, and self-esteem, 4) enlightening - the capability of the elderly people about memory, reasonable thinking, communication, planning, and problem solving, and 5) calmness - the recognition and understanding of one's own feeling, the emotion control, and the ability to handle the emotional state that occurs effectively.

In addition, the causal relationship between well-being, stress management, and mental well-being of the elderly people was relevant to the empirical data, which means both well-being and stress management had an effect on mental well-being of the elderly people in Bangkok. This is relevant to the study of Wu and Zhang (2011) who studied about the impact of isolation and loneliness on elderly well-being. The results of the study show there is a connection between isolation and elderly well-being, and a connection between loneliness and elderly well-being. Both isolation and loneliness become the main obstacles in living the rest of their life. The isolation and loneliness have an influence on health condition of the elderly people, and related diseases also affect the health of the elderly people. In contrast, the experience about loneliness of the elderly people often leads to poor quality of life and poor living conditions of the elderly people. This is also relevant to the study of Talodphop, Pratumtone, Reunkon, and Mopuang (2014) who studied about factors affecting stress of elderly in Ban-Klong District Amphur Muang, Phitsanulok Province. Its results show that the first factor affecting stress of elderly is the personal factor, such as aging, injury and illness. The second is the financial factor: having not enough money to spend. The third is the family factor, such as the death of their spouse. The forth is the social factor, such as being the leader. The last is the environment factor, such as disaster. The activities of the elderly people to release stress are watching television or movie, doing hobbies, making merit and charity, having plenty of rest, practicing meditation, and praying. When the elderly people can handle the stress, they will have good mental health and live happily. This is also relevant to the study of Chao (2010) who studied about managing stress and maintaining well-being: social support, problem-focused coping, and avoidant coping. Its results show that among students with high levels of social support, there is no statistically significant relationship between stress and well-being. In addition, although students had high levels of social support or avoiding problems, the relationship between stress and well-being was in the negative direction. Lower social support relates to lower well-being than does higher support, and a similar finding appears on the patterns of interaction of stress and avoidant coping. When perceiving low support, students with frequent avoidant coping had the lowest scores on well-being. These results indicated that college students who have low social support and frequent use of avoidant coping were most vulnerable to stress, and infrequent use of avoidant coping would not worsen the association between stress and well-being. According to the study of Tongvichean (2007) about psychological well-being of the elderly in Samutprakan Province, the correlation of developmental tasks of aging families, access to health care services, and self-care behaviors were statistically related with psychological well-being. These factors jointly explained about $45.8 \%$ of the variance of psychological well-being of the elderly. In addition, the study of Thongsuk (2016) showed that factors influencing psychological wellbeing among older adults, social support, perceived self-efficacy, and perceived health status together can explain $24 \%$ of the variance of psychological well-being. The strongest predictor was social support, followed by perceived self-efficacy, and perceived health status.

\section{Recommendations:-}

\section{Recommendations for this research:-}

The research results can be implemented in order to create mental well-being for the elderly in the community of Bangkok, as follows:-

1. The community or the elderly caregiver should pay attention to the nutrition of food, and to recommend avoiding or abstaining from smoking, alcohol, and promoting regular exercise.

2. The community or the elderly caregiver should support the elderly people to do their favorite hobbies, to not let them get struck in pressure, and to take them to go sight-seeing or field trips.

3. The community or the elderly caregiver should support the elderly people to create good relationship with their neighbors, and create activities for the elderly to transfer knowledge to society and tocreate pride in their past life. 


\section{Recommendations for future research:-}

1. There should be the in-depth qualitative research in order to support the quantitative research.

2. There should be the additional study on factors affecting mental well-being of the elderly people in other aspects, for example, a case study of the elderly people in Northern, North-eastern, East, or Southern of Thailand, this is because the elderly people in each region have different living conditions and environments.

\section{References:-}

1. Channuwong, S. \& Kantatian, W. (2012). Stress Management Strategies for Managers: An Integration of Eastern and Western Approaches. European Journal of Social Sciences, 29(1), 66-75.

2. Chao, R. C. L. (2010). Managing Stress and Maintaining Well-Being: Social Support, Problem-Focused Coping, and Avoidant Coping. Journal of Counseling \& Development, 89, 338-348.

3. Duangkaew, T., and Dech-Udom, H. (2007).The Health Behavior of Elderly Prongmadua Subdistrict, Meung District, Nakornprathom Province. Nakhon Pathom: Nakhon Pathom Rajabhat University.

4. Foundation of Thai Gerontology Research and Development institute. (2015). Aged Society 60+. Retrieve from file:///C:/Users/com/Downloads/factsheet-aw-ok-1-edit.pdf

5. Jutha, W., Luemchan, D., Chandrachot, K. (2012).Situation and Tendency of Stress of Thai People during April 2009 - January 2012. Nonthaburi: Department of Mental Health, Ministry of Public Health.

6. Ketpitchwattana, J., Sangtienchay, C., and Angsuroj, Y. (2000).Relationship between family support and mental happiness of Thai elderly.The Journal of Demography, 17(2), 1-18.

7. Naidoo, J. and Wills, J. (2009).Foundations for Health Promotion. ( $3^{\text {rd }}$ ed.). London: BaillierTindall.

8. Noiwat, O. (2012). Health and Life Quality.Journal of Health Science Online. Retrieve from http://www.stou.ac.th/Schools/Shs/booklet/book55_/3pbhealth.html

9. Phusuwan, N. (2014). The stress of elderly in a district, Sakonnakhon Province. Journal of the Humanities and Social Sciences. $10^{\text {th }}$ Academic Conference at Mahasarakram University.

10. Ruderman, N.B., Saha, A.K., and Kraegen, E.W. (2002). Mini review: malonyl CoA, AMP-activated protein kinase, and adiposity. Endocrinology.

11. Ryff, C. D., \& Keyes, C. L. M. (1995). The structure of psychological well-being revisited. Journal of Personality and Social Psychology, 69(4), 719- 727.

12. Seligman, M.E.P. (2011). Flourish: A Visionary New Understanding of Happiness and Well-Being. New York: Free Press.

13. Social Development Office of Bangkok Metropolitan Administration. (2017). Information on the elderly in the area of 50 districts in Bangkok. Retrieve from http://www.bangkok.go.th/social/page/sub/7600/ informationon-the-elderly-in-the-area-of-50-districts-in-Bangkok.

14. Songtub, A., Suklim, N., and Raksanam, B. (2013).Development of Health Promotion Behaviors Model of the Elderly in Kuan Tan District, Kantang District, Trang Province.

15. Talodphop, K., Pratumtone, W., Reunkon, A., and Mopuang, R. (2014). Factors Affecting Stress of Elderly in Ban-Klong District Amphur Muang, Phitsanulok Province. RMUTP Research Journal Special Issue, The $5^{\text {th }}$ Rajamangala University of Technology National Conference.

16. Thongsuk, Y. (2016). Factors Influencing Psychological Well-being among Older Adults, Social Support. Master of Nursing Science, Department of Nursing, Mental Health and Psychiatry, Faculty of Nursing, Burapha University.

17. Tongvichean, T. (2007). Psychological Well-being of the Elderly in Samutprakan Province. M.Sc. (Public Health) Major in Public Health Nursing, Mahidol University.

18. Trireungworawat, B. (2017). Department of Mental Health recommends elderly people to use the 5 Happiness in Thailand 4.0 Era. Retrieve from http://www.thansettakij.com/content/182564

19. Wimolsiri, P. (2017). Super Aged Society in 2021, Population Development Plan for 20 Years. Retrieve from https://www.thairath.co.th/content/956700

20. Wu, Y. and Zhang, C. (2011). The Impact of Isolation and Loneliness on Elderly Well-being. General Nursing, University of Applied Science. 